\title{
An Application of a Hybrid Fuzzy Multi-Criteria Decision-Making Approach in Managing Equipment Hazards in Woodworking
}

\author{
Egberto F. Selerio Jr. ${ }^{1,2 *}$, Redjie D. Arcadio ${ }^{3}$, Gerwine J. Medio ${ }^{3}$, Manolito A. Nacua ${ }^{3}$, Girly A. Pedregosa ${ }^{3}$ \\ ${ }^{1}$ Department of Industrial Engineering, University of San Jose-Recoletos, Corner Magallanes St. \& P. Lopez St., Cebu City, \\ 6000 Cebu, Philippines \\ ${ }^{2}$ Department of Industrial Engineering, University of San Carlos, Gov. M. Cuenco Avenue, Barangay Talamban, Cebu City, \\ 6000 Cebu, Philippines \\ ${ }^{3}$ Department of Industrial Technology, Cebu Technological University, Corner M.J. Cuenco Ave. \& R. Palma St., Cebu City, \\ 6000 Cebu, Philippines
}

Corresponding Author Email: 20102931@usc.edu.ph

https://doi.org/10.18280/ijsse.100411

Received: 25 May 2020

Accepted: 27 July 2020

\section{Keywords:}

woodworking, occupational health and safety, risk management, fuzzy Best-Worst method, fuzzy Delphi method

\begin{abstract}
Woodworking is among the most dangerous activities with manifold risks to occupational safety and health of operators. Most of these risks are associated with the design of woodworking equipment. In this regard, the identification of woodworking equipment hazards (WEHs) is essential for improving safety. However, collective the identification and assessment of WEHs is not yet attempted in the woodworking literature, especially in the context of a developing country whose woodworking sector is more exposed to these risks. To address this gap, this paper employs a double triangular fuzzy Delphi method (FDM) in conjunction with the fuzzy Best-Worst method (F-BWM). The FDM was employed to select relevant WEHs, which are collectively sourced from previous literature, while the F-BWM is used to rank the relevant WEHs. The findings of this paper show that the risks posed by lack of "kickback safeguards" are the most important, while the risks posed by inadequate "maintenance functions" are the least important. The proposed algorithmic framework of this paper can help managers, occupational safety and health professionals, and woodworking firms in developing countries like the Philippines to build the capability they need to address WEHs and, to some extent, improve safety practices in the woodworking industry.
\end{abstract}

\section{INTRODUCTION}

Risks are inevitable in a complex activity like woodworking [1]. Cases of occupational health and safety hazards (OHSHs) are prevalent in the woodworking sector [2]. These OHSHs are mostly instigated by the equipment commonly utilized in performing woodworking processes [3]. Woodworking equipment are commonly comprised of blades, rotating parts, high-powered components, among others. These components can pose OHSHs to woodworkers [4]. Woodworking equipment are complex pieces of technology. Therefore, their safety management warrants for a systematic hazard assessment.

Woodworking equipment hazards (WEHs) are defined herewith as risks associated with the design of equipment, which can place woodworking operators at risk. WEHs vary little across different woodworking equipment. This phenomenon is due to the commonality in their design functions, components, and handling [2]. In this view, WEHs can be approached collectively. Furthermore, the evaluation of WEHs allows for their prioritization, which is critical for efficient safety management.

The assessment of WEHs is critical for the minimization of work-related accidents and occupational illnesses [5]. It can also facilitate woodworking equipment design. Among the common reasons for innovating woodworking equipment is to address WEHs. Sheldon and Singh [6] proposed a router with an automatic dust collection system. The end-view of their innovation is to eliminate wood dust suspension in air. Chukarin et al. [7] identified that the installment of dust reduction protocols in woodworking equipment may increase noise. Their study proposed a design for a "noise-dust woodworking machine" to address this issue. Pavlovic and Fragassa [8] developed a woodworking ballistic impact protection for woodworking equipment. Weaver III et al. [9] suggested flesh sensing mechanisms for woodworking equipment with highly exposed blades (see also Ref. [10]). These design innovations were developed as a consequence of observing the hazards that they address. Hazard assessment, therefore, provides the foundation for successful health, safety, and safety management through design. Furthermore, the assessment of WEHs can guide designers in prioritizing safety aspects of woodworking equipment leading to optimal design decisions. Apart from design interventions, assessment of WEHs can also be employed for evaluating the safety of woodworking equipment to improve existing handling practices.

Although sporadically identified, WEHs were widely recognized in previous literature. For instance, Dąbrowski and Górski [4] elaborated that equipment 'kickback' may be fatal to workers, especially in the case of tools with non-cylindrical body shapes (see also Refs. [8-10]). On the other hand, Weaver 
III et al. [9] recognized that the lack of flesh sensing mechanisms increases the probability of injurious contact to workers, especially when operating equipment with exposed blades. According to the study [11], high-speed projection of broken parts of saw equipment is primarily caused by inadequate saw dimensioning. While some studies did not explicitly identify the specific hazards associated with injuries and illnesses, the apparent patterns that arise from the source, severity, nature, and cause of injuries and illnesses can provide insight into the particular WEHs that they are associated with. For instance, limb amputation due to contact with the blades can be associated with several WEHs such as the inadequate guards at the point of operation [12], loose machine adjustment mechanism [2], inadequate interlocks [13], inadequate warning mechanisms for coasting blades [2], among others.

Table 1. The WEHs

\begin{tabular}{|c|c|c|}
\hline No. & WEH & $\begin{array}{l}\text { Brief Description } \\
\end{array}$ \\
\hline WEH1 & Exposed blades & Dangerous and sharp-edged components of machinery are exposed during normal operations. \\
\hline WEH2 & Inadequate stock controls & $\begin{array}{l}\text { Handling small stock pieces requires the hand to be in proximity to dangerous or sharp } \\
\text { equipment components. }\end{array}$ \\
\hline WEH3 & Adjustment functions & $\begin{array}{l}\text { Faulty or quickly loose design of adjustment mechanism (e.g., joints) for the machine of the } \\
\text { guard. }\end{array}$ \\
\hline WEH4 & Placement of controls & $\begin{array}{c}\text { Controls (e.g., buttons) are placed where they can easily be obstructed, accidentally moved, } \\
\text { among others. }\end{array}$ \\
\hline WEH5 & De-energizing functions & $\begin{array}{l}\text { Requires highly manual lockout/tag-out procedures, which causes the possibility of contact with } \\
\text { the energized machine. }\end{array}$ \\
\hline WEH6 & Warning lights & Unclear or confusing warning lights for indicating potentially hazardous situations. \\
\hline WEH7 & $\begin{array}{l}\text { Guards at point of } \\
\text { operation }\end{array}$ & Absence of guards for protecting body parts at the point of operation. \\
\hline WEH8 & Visual supports & Confusing labels or colors for highlighting critical components of the WE. \\
\hline WEH9 & Alarm system & An inadequate alarm system or sensor-based auto-shutdown function or lack thereof. \\
\hline WEH10 & Interlock guards & $\begin{array}{l}\text { Inadequate interlocks so that employees cannot easily bypass, remove, or otherwise tamper with } \\
\text { the guard or lack thereof. }\end{array}$ \\
\hline WEH11 & Unclear fonts & Unreadable font size or font style used for indicating instructions, labels, among others. \\
\hline WEH12 & Requires freehand sawing & $\begin{array}{c}\text { Freehand sawing increases the likelihood of an operator's hands coming in contact with the } \\
\text { blade. }\end{array}$ \\
\hline WEH13 & Friction controls & Low friction controls to minimize abrasion or lack thereof. \\
\hline WEH14 & Not adjustable guard & $\begin{array}{l}\text { The guard must adjust to the thickness of the material being cut and remain in contact with it, } \\
\text { especially in saw Woodworking equipment. }\end{array}$ \\
\hline WEH15 & Blade retraction & Inadequate automatic blade retraction mechanism or lack thereof. \\
\hline WEH16 & Warning system & Inadequate interactive warning mechanisms or lack thereof. \\
\hline WEH17 & Wheel brakes & Inadequate wheel brakes for stopping coasting blades or lack thereof. \\
\hline WEH18 & Blade tension sensors & Inadequate blade tension sensing mechanism or lack thereof \\
\hline WEH19 & Stock holding mechanism & $\begin{array}{c}\text { Inadequate or non-integrated holding mechanism for handling small or narrows stock during } \\
\text { cutting or lack thereof. }\end{array}$ \\
\hline WEH 20 & Rotary guards & Inadequate guards for rotary or reciprocating parts or lack thereof. \\
\hline WEH 21 & $\begin{array}{l}\text { Crush protection } \\
\text { mechanism }\end{array}$ & $\begin{array}{l}\text { Inadequate protection mechanisms for avoiding the machine or its parts from crushing the } \\
\text { operator or operator's body part. }\end{array}$ \\
\hline WEH 22 & Stop controls & Inadequate controls for stopping the equipment during emergencies. \\
\hline WEH 23 & Spindle brakes & Inadequate spindle braking system or lack thereof. \\
\hline WEH24 & $\begin{array}{l}\text { Guards for in-running nip } \\
\text { points }\end{array}$ & Inadequate guards for in-running nip points or lack thereof. \\
\hline WEH 25 & Inspection panel & Unclear, easily scratched or improperly positioned inspection panel or lack thereof. \\
\hline WEH26 & Kickback safeguards & Inadequate guards for avoiding kickbacks or lack thereof. \\
\hline WEH27 & Blade material & Defective material used for saw blade- easily broken, bent, dulled or damaged. \\
\hline WEH 28 & Maintenance functions & Difficult to maintain or risky to perform maintenance. \\
\hline WEH 29 & Stock handle & Loose stock handle or handle become quickly loose. \\
\hline WEH30 & Blade design & Inadequate design, shape, or size of blades. \\
\hline WEH31 & Shield guards & Inadequate guards for flying stock material and equipment projectiles or lack thereof. \\
\hline WEH32 & Shield guard material & Material for shield guard can easily be punctured. \\
\hline WEH33 & Shield guard design & Inadequate guard design, size, or shape for performed operation. \\
\hline WEH34 & Cutter head stability & The unbalanced cutter head can cause severe injuries to the operator. \\
\hline WEH35 & Heat controls & Inadequate controls for monitoring the heat of equipment or lack thereof. \\
\hline WEH36 & Power guards & Inadequate guards for power transmission apparatus or lack thereof. \\
\hline WEH37 & Cables and pipes & Trip hazards and electric hazards posed by power cables or pipes. \\
\hline WEH38 & Grounding mechanism & Inadequate grounding system of the WE for reducing electrocution of the operator. \\
\hline WEH39 & $\begin{array}{l}\text { Auto-restart prevention } \\
\text { mechanism }\end{array}$ & Lack of preventive mechanism for automatic restarting. \\
\hline WEH40 & Shut-off protocols & $\begin{array}{l}\text { Lack of maintenance shut off protocols for avoiding electrocution and other injuries that can } \\
\text { occur during maintenance of WE. }\end{array}$ \\
\hline WEH41 & Noise controls & Inadequate noise source control or lack of sound-absorbent hoods around points of operation \\
\hline WEH42 & Damping suspension & Inadequate anti-vibration mechanism or lack thereof. \\
\hline WEH43 & Anchors & Not anchored on a solid foundation for minimizing movement of equipment. \\
\hline WEH44 & Local exhaust ventilation & Inadequate dust reduction functions or lack thereof. \\
\hline
\end{tabular}


While WEHs are widely recognized, an approach for assessing WEHs is not yet explored. This knowledge gap is critical for the management of occupational health and safety of operators. Reliable and proactive approaches to hazard assessment is crucial in preventing critical injuries or even death [2]. It is also essential in preventing costly disruptions in production (e.g., downtime) that are caused by accidents [4]. An in-depth analysis of WEHs is also warranted so that leverage strategies may be developed to address them. The primary organizational benefit of hazard assessment includes not only the improvement of workplace health and safety, but business performance as well [3]. While the innovative developments previously discussed addresses WEHs, it is counterintuitive, to some extent, that although woodworking equipment share common characteristics, a collective identification of WEHs is narrowly attempted in the current literature. Moreover, the furtherance of theoretical methods for assessing them so that hazard assessment may be integrated into the innovation process is also narrowly explored.

Indifference to theoretical approaches regarding hazard management has been a problem in the domains of woodworking research for a long time. Industrial situations often highlight a considerable divergence between the foreseen theoretical reliability and the operational reliability observed in the field. The examination performed by Fadier and Ciccotelli [14] discovered that the majority of the research in the domains of design and innovation takes the form of practical experiments, with little theoretical work. This issue persists in the form of haphazard innovation of woodworking equipment. Previous studies consistently fail to systematically present sufficient justification for placing priority to a $\mathrm{WEH}$ over others in the innovation of woodworking equipment. Most of the time, their justification is presented pragmatically and with little theoretical background. With this haphazard innovation procedure several critical factors may be overlooked (e.g., relative importance of WEHs). Thus, an approach that strikes a balance between the theoretical and operational aspects of innovation is warranted.

Although concerns presented in various studies are diverse, those that deal with the question of hazard assessment and how it can be integrated into the innovation process of woodworking equipment are rare. This may be instigated by the lack of understanding of the WEHs, which limits the development of frameworks for their evaluation. Thus, collective identification of WEHs may be instrumental in this regard. It may expand the general understanding of the obstacles that need to be addressed in developing designs for woodworking equipment, so that hazards are eradicated or minimized effectively and efficiently. In this view, the identification of WEHs may facilitate the efficient innovation of woodworking equipment, which, as previously discussed, has been proven essential in safety management. The standards provided by the Occupational Safety and Health Association (OSHA) [2] intends to serve as a "guide for protecting workers from woodworking hazards." In their standards, 44 WEHs can be derived, which are presented in Table 1. As established in previous discussions, prioritization of WEHs is essential. Therefore, the selection of the most relevant WEHs among the initial set obtained from the study [2] is warranted. This idea is justified because prevalent WEHs may vary with the case environment.

For instance, equipment employed in first world countries is expected to be more technocratic than in developing countries. Thus, WEHs that exist in those settings may not be as potent as in others. Arimbi et al. [3] emphasized that in lowincome settings, highly manual and less guarded equipment are employed for performing woodworking processes, which result in a high occurrence of woodworking injuries. In this respect, it is essential to screen through the identified WEHs so that the most relevant ones are assessed in the context of a developing country. The screening was performed in this study using the fuzzy Delphi method (FDM). Apart from increasing the relevance of the assessment, dimensional reduction by screening WEHs makes the application of other models less complicated, which allows for in-depth analysis. In conjunction with the FDM, the fuzzy best-worst method (FBWM) is employed in this study to measure the relative importance of the WEHs for prioritization purposes. The integration of the FDM and the F-BWM expands the analysis WEHs, which is not yet attempted in previous literature.

The objective of this paper is to study and compare the various attributes linked to the safety management woodworking equipment. In doing so, an integrated fuzzy multicriteria decision making (MCDM) approach, which consists of the FDM and F-BWM, is employed to measure the relative importance of WEHs. The applicability of the proposed fuzzy MCDM approach employed in this study is tested in the Philippine setting. This paper differs from past studies in three-folds. First, it pioneers an in-depth analysis for measuring the importance WEHs leading to their prioritization. Second, this paper is the first to employ MCDM models in the analysis of WEHs. Finally, this paper leads the analysis of WEHs in the context of a developing country like the Philippines. Apart from the introduction section, this paper is organized as follows: Section 2 details the methodology. Section 3 presents the case application adopted in this work. Section 4 highlights the results and discussions of the case study, and it ends with a conclusion and discussion of future work in Section 5.

\section{METHODOLOGY}

In assessing the identified WEHs, this paper uses a semiquantitative approach in two phases. In the first phase, among the initial list of WEHs from the literature, the relevant WEHs were selected in the context of a developing country Philippines. In the second phase, the relevant WEHs are prioritized. A more detailed description of the research process is presented in the following section. In employing the procedures in both the first and second phase, this paper makes use of expert decisions. In general, the number of experts consulted in decision making problems commonly range from three to 15 [15]. In this study, there are five experts consulted. The five experts were selected from both industry and academia. Since this study involves both practical and theoretical aspects of hazard management in woodworking, the researchers made sure that the experts are multidimensionally competent and that their experience should compose of theoretical, technical, and managerial experiences. The demographics of the experts are presented in Table 2.

The method employed in this study is based on the judgements of the selected experts, and does not rely on previous historical data being available. Moreover, the method is typically intended to provide a judgement or opinion on the specific subject area, rather than producing a quantifiable measure or result. Because of this, the method can easily work 
well in new areas that are frequently subject to unpredictable forces, which are not easily quantifiable in most of the cases [15].

Table 2. Demographic information of the experts

\begin{tabular}{cccc}
\hline Expert & Position & $\begin{array}{c}\text { Highest } \\
\text { Qualification }\end{array}$ & $\begin{array}{c}\text { Work Experience } \\
\text { (Years) }\end{array}$ \\
\hline Expert 1 & Professor & Doctorate & 13 \\
Expert 2 & Professor & Doctorate & 10 \\
Expert 3 & Manager & Masters & 11 \\
Expert 4 & Manager & Masters & 13 \\
Expert 5 & Manager & Masters & 12 \\
\hline
\end{tabular}

Since this paper employs expert decisions in assessing multiple WEHs, it can be viewed as a multi-criteria decisionmaking (MCDM) problem. Moreover, this paper employs MCDM models in integration with fuzzy set theory [16] to factor-in the vagueness and uncertainty of expert judgments. The MCDM models employed in this paper are the fuzzy Delphi method (FDM) and the fuzzy Best-Worst method (FBWM). The procedures undertaken in this study to employ the previously discussed MCDM models are detailed as follows:

Step 1. (Build the initial list of WEHs). The WEHs were sourced from the standard manual provided in the study [2]. The initial list of WEHs are presented in Table 1. There were 44 WEHs identified.

Step 2. (Collect expert opinions). To examine the importance of these proposed 44 WEHs, five experts used an interval range, from zero (0) to ten (10), to assess them.

Step 3. (Establish the triangular fuzzy function) The evaluation values are divided into maximum and minimum groups. The maximum interval value and the minimum interval value present the experts' most optimistic cognition and conservative cognition of the quantitative score for the WEH, respectively. The computing formula is illustrated as follows:

Assuming the optimistic cognition evaluation value of the significance of the $j$ th WEH that is given by the $i$ th expert where $i=\{1,2, \ldots, n\}$ and $j=\{1,2, \ldots, m\}$ is $\check{O}_{i j}=$ $\left(L_{i j}, M_{i j}, U_{i j}\right)$; then the optimistic cognition fuzzy weighting of the $j$ th WEH is $\check{O}_{j}=\left(L_{j}, M_{j}, U_{j}\right), j=\{1,2, \ldots, m\}$ where $L_{j}, M_{j}$, and $U_{j}$ are calculated, as shown in Eq. (1). Consequently, the experts' conservative cognition evaluation value is $\check{C}_{i j}=\left(l_{i j}, m_{i j}, u_{i j}\right)$ and the conservative cognition fuzzy weighting of the $j$ th WEH is $\check{C}_{j}=\left(l_{j}, m_{j}, u_{j}\right), j=$ $\{1,2, \ldots, m\}$ where $l_{j}, m_{j}$, and $u_{j}$ are calculated, as shown in Eq. (2)

$$
\begin{gathered}
L_{j}=\min _{i}\left\{L_{i j}\right\}, M_{j}=\left(\prod_{i=1}^{n} M_{i j}\right)^{\frac{1}{n}}, U_{j}=\max _{i}\left\{U_{i j}\right\} \\
l_{j}=\min _{i}\left\{l_{i j}\right\}, m_{j}=\left(\prod_{i=1}^{n} m_{i j}\right)^{\frac{1}{n}}, u_{j}=\max _{i}\left\{u_{i j}\right\}
\end{gathered}
$$

The relationship between the TFNs, $\check{O}_{j}=\left(L_{j}, M_{j}, U_{j}\right)$ and $\check{C}_{j}=\left(l_{j}, m_{j}, u_{j}\right)$, is to examine the consistency of the experts' opinions, and is called the double triangular number method.

Step 4. (Consistency test by double triangular fuzzy number method) Figure 1 shows the relationship between the optimistic and conservative TFNs. There are two conditions for certifying the consistency of the experts' opinions [17]. First, if the value of $L_{j} \geq u_{j}$, then the experts' opinions are consistent. Second, if the value of $L_{j}<u_{j}$, and the value of $L_{j}, u_{j}$ is between the values of $M_{j}$ and $m_{j}$, then the experts' opinions are consistent. If neither of the above two conditions are satisfied, then the experts' opinions are inconsistent. The consistency value of the gray interval for the $j$ th $\mathrm{WEH}$ is $G_{j}=$ $\frac{M_{j}+m_{j}}{2}$. Next, the threshold $\alpha$ is set according to the actual situation. If $G_{j} \geq \alpha$, then it will be selected as the evaluation index, and $j$ th WEH will be accepted. If not, the $j$ th WEH will be deleted.

Step 5. (Identify the relevant WEHs) From the initial list of WEHs, the relevant WEHs are extracted and used in application for the F-BWM. Suppose there are $n$ WEHs selected, then the set of relevant WEHs are expressed as $\left\{c_{1}, c_{2}, \ldots, c_{n}\right\}$.

Step 6. (Determine the best - most important - and the worst - least important - WEH) Based on the set of relevant WEHs, the best WEH and the worst WEH are identified by the experts in this step. The best WEH is represented as $c_{B}$, and the worst WEH is represented as $c_{W}$.

Step 7. (Execute the fuzzy reference comparisons for the best $W E H)$ The fuzzy reference comparison includes two parts: one part is the pairwise comparison $\breve{a}_{i j}$ in the case, that $i$ is the best WEH, and here $c_{i}$ is the best $\mathrm{WEH}, c_{B}$; the other is the pairwise comparison $\breve{a}_{i j}$ in the case, that $j$ is the worst $\mathrm{WEH}$, and here $c_{j}$ is the worst $\mathrm{WEH}, c_{W}$. In this step, the first part will be performed. By using the linguistic terms of the experts listed in Table 3, the fuzzy preferences of the best WEH over all the WEH can be determined. Then, the obtained fuzzy preferences are transformed to TFNs according to the transformation rules shown in Table 1. The obtained fuzzy Best-to-Others vector is:

$$
\check{A}_{B}=\left(\check{a}_{B 1}, \check{a}_{B 2}, \ldots, \check{a}_{B n}\right)
$$

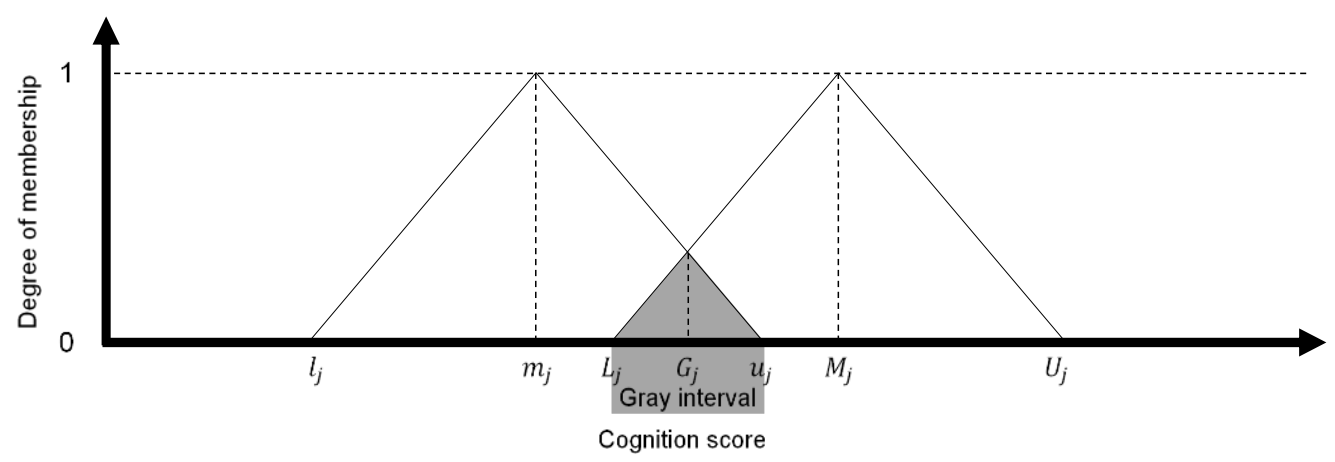

Figure 1. The relationship between the optimistic and conservative TFNs 
Table 3. Linguistic terms, their corresponding TFN and consistency index for F-BWM

\begin{tabular}{cccccc}
\hline Linguistic terms & $\begin{array}{c}\text { Equally important } \\
(\text { EI) }\end{array}$ & $\begin{array}{c}\text { Weakly important } \\
(\text { WI })\end{array}$ & $\begin{array}{c}\text { Fairly important } \\
(\text { FI })\end{array}$ & $\begin{array}{c}\text { Very important } \\
(\text { VI) }\end{array}$ & $\begin{array}{c}\text { Absolutely } \\
\text { important (AI) }\end{array}$ \\
\hline$\breve{a}_{B W}$ & $(1,1,1)$ & $\left(\frac{2}{3}, 1, \frac{3}{2}\right)$ & $\left(\frac{3}{2}, 2, \frac{5}{2}\right)$ & $\left(\frac{5}{2}, 3, \frac{7}{2}\right)$ & $\left(\frac{7}{2}, 4, \frac{9}{2}\right)$ \\
Consistency index & 3.00 & 3.80 & 5.28 & 6.69 & 8.04 \\
\hline
\end{tabular}

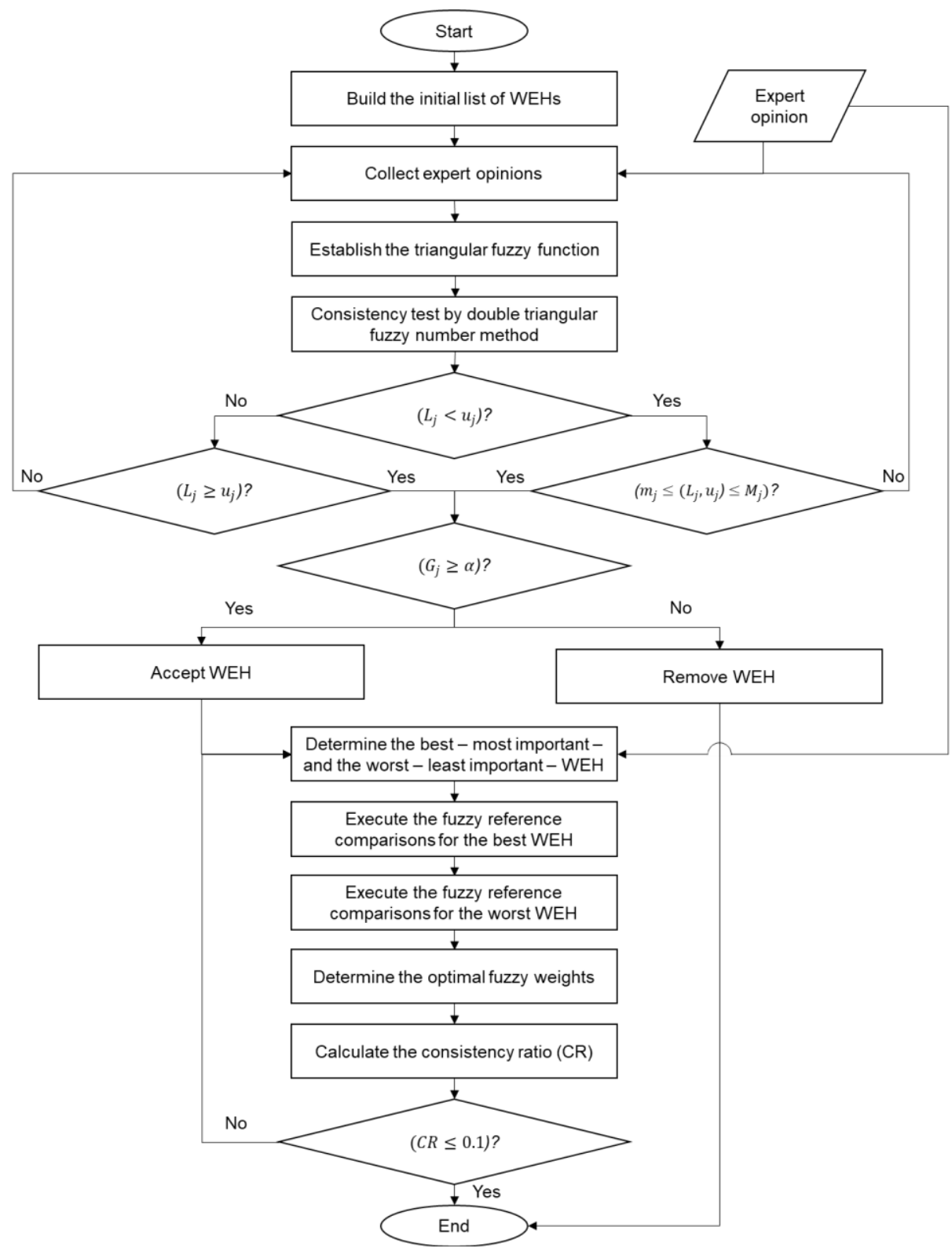

Figure 2. The algorithmic flow of the integrated FDM and F-BWM approach

Step 8. (Execute the fuzzy reference comparisons for the worst WEH) In this step, the other part of the fuzzy reference comparison will be done. By using the linguistic evaluations of experts listed in Table 3, the fuzzy preferences of the other WEHs over the worst WEH are determined. They are then transformed into TFNs according to the transformation rules listed in Table 3. The fuzzy Others-to-Worst vector can be obtained as:

$$
\check{A}_{W}=\left(\check{a}_{1 W}, \check{a}_{2 W}, \ldots, \check{a}_{n W}\right)
$$

where, $\breve{A}_{W}$ represents the fuzzy Others-to-Worst vector; $\check{a}_{i W}$ represents the fuzzy preference of WEH $i$ over the worst WEH $c_{W}, i=\{1,2, \ldots, n\}$. It can be known that $\check{a}_{W W}=(1,1,1)$.
Step 9. (Determine the optimal fuzzy weights: $\breve{w}_{1}^{*}, \breve{w}_{2}^{*}, \ldots, \breve{w}_{n}^{*}$ ) The optimal fuzzy weight for each WEH is the one where for each fuzzy pair $\frac{\breve{w}_{B}}{\widetilde{w}_{j}}$ and $\frac{\breve{w}_{j}}{\check{w}_{W}}$, it should have $\frac{\breve{w}_{B}}{\widetilde{w}_{j}}=\check{a}_{B j}$ and $\frac{\breve{w}_{j}}{\breve{w}_{W}}=$ $\check{a}_{j W}$. To satisfy these conditions for all $j$, it should determine a solution where the maximum absolute gaps $\left|\frac{\breve{w}_{B}}{\breve{w}_{j}}-\breve{a}_{B j}\right|$ and $\left|\frac{\breve{w}_{j}}{\breve{w}_{W}}-\breve{a}_{j W}\right|$ for all $j$ are minimized. It should be noted that $\breve{w}_{B}$, $\breve{w}_{j}$, and $\breve{w}_{W}$ in F-BWM are TFNs, which are very different from that in BWM. In some cases, $\breve{w}_{j}=\left(l_{j}^{w}, m_{j}^{w}, u_{j}^{w}\right)$ is preferred for an optimal alternative selection. By assuming some of the weights equal to one and non-negativity constraints, the F-BWM model is expressed as follows [18]: 


$$
\begin{gathered}
\min \max _{j}\left\{\left|\frac{\breve{w}_{B}}{\breve{w}_{j}}-\check{a}_{B j}\right|,\left|\frac{\breve{w}_{j}}{\breve{w}_{W}}-\check{a}_{j W}\right|\right\} \\
\text { s.t.: } \\
\sum_{j=1}^{n} R\left(\check{w}_{j}\right)=1 \\
l_{j}^{w} \leq m_{j}^{w} \leq u_{j}^{w} \text { for all } j \\
l_{j}^{w} \geq 0 \text { for all } j
\end{gathered}
$$

The model (5) can be re-written as follows:

$$
\begin{gathered}
\min \check{\xi} \\
\text { s.t.: } \\
\left|\frac{\breve{w}_{B}}{\breve{w}_{j}}-\breve{a}_{B j}\right| \leq \check{\xi} \text { for all } j \\
\left|\frac{\breve{w}_{j}}{\breve{w}_{W}}-\check{a}_{j W}\right| \leq \check{\xi} \text { for all } j \\
\sum_{j=1}^{n} R\left(\breve{w}_{j}\right)=1 \\
l_{j}^{w} \leq m_{j}^{w} \leq u_{j}^{w} \text { for all } j \\
l_{j}^{w} \geq 0 \text { for all } j
\end{gathered}
$$

where, $\check{\xi}=\left(l^{\xi}, m^{\xi}, u^{\xi}\right), l^{\xi} \leq m^{\xi} \leq u^{\xi}$, and supposing $\check{\xi}^{*}=$ $\left(k^{*}, k^{*}, k^{*}\right), k^{*} \leq l^{\xi}$.

Furthermore, after obtaining fuzzy weights, the graded mean integration representation (GMIR) is used to transform the fuzzy weight of WEH to crisp weights. The GMIR formula is as follow:

$$
R\left(\breve{w}_{j}\right)=\frac{l_{j}^{w}+4 m_{j}^{w}+u_{j}^{w}}{6}
$$

Step 10. (Calculate the consistency ratio) The consistency ratio is employed to check how consistent a fuzzy comparison is. There is full consistency in fuzzy pairwise comparison vector while $\breve{a}_{B j} \times \breve{a}_{j W}=\breve{a}_{B W}$. In a case wherein $\breve{a}_{B j} \times$ $\check{a}_{j W} \neq \check{a}_{B W}$, inconsistency occurs. Inconsistency will reach its maximum value $\breve{\xi}$ when both $\check{a}_{B j}$ and $\check{a}_{j W}$ are equal to $\check{a}_{B W}$. Considering the occurrence of the most significant inequality, according to the equality relation $\frac{\breve{w}_{B}}{\breve{w}_{j}} \times \frac{\breve{w}_{j}}{\breve{w}_{W}}=\frac{\breve{w}_{B}}{\breve{w}_{W}}$, Eq. (8) obtained as follows [18]:

$$
\left(\check{a}_{B W}-\check{\xi}\right) \times\left(\check{a}_{B W}-\check{\xi}\right)=\left(\check{a}_{B W}+\check{\xi}\right)
$$

Eq. (7) can be rewritten as follows:

$$
\check{\xi}^{2}-\left(1+2 \check{a}_{B W}\right) \check{\xi}+\left(\check{a}_{B W}{ }^{2}-\check{a}_{B W}\right)=0
$$

where, $\check{\xi}=\left(l^{\xi}, m^{\xi}, u^{\xi}\right)$ and $\check{a}_{B W}=\left(l_{B W}, m_{B W}, u_{B W}\right)$. For $\check{a}_{B W}=\left(l_{B W}, m_{B W}, u_{B W}\right)$ the maximum fuzzy value cannot exceed $9 / 2$. By using upper bound $u_{B W}$ in consistency index calculation, all the data affiliated to TFN $\check{a}_{B W}$ can use this consistency index. Meanwhile $\breve{\xi}$ is represented as a crisp value of $\xi$. By these considerations, to calculate the consistency ratio in F-BWM, we need to measure Eq. (10) for all $u_{B W}$.

$$
\check{\xi}^{2}-\left(1+2 u_{B W}\right) \check{\xi}+\left(u_{B W}^{2}-u_{B W}\right)=0
$$

where, $u_{B W}=\left\{1, \frac{3}{2}, \frac{5}{2}, \frac{7}{2}, \frac{9}{2}\right\}$, respectively. By solving Eq. (10) for different $u_{B W}$, the maximum possible $\xi$ can be found, which is employed as the consistency index for F-BWM [18]. The obtained consistency index (CI) with regards to different linguistic terms of decision-makers for F-BWM are listed in Table 3. The algorithmic flow of the hybrid FDM and F-BWM approach is presented in Figure 2.

\section{CASE STUDY BACKGROUND}

To test the applicability of the proposed approach, this paper employs a case study in the Philippine setting. The Philippines is a developing country in Southeast Asia with a productive woodworking sector. According to the Philippine Statistics Authority (PSA) [19], the woodworking sector of the country led its fourteen other major sectors in terms of growth in the following performance metrics: value of production index (118.5\%), volume of production index $(116.7 \%)$, value of net sales index (40.6\%), and volume of net sales index (40.2\%). However, it revealed that, machines and equipment, among identified agents of injuries, has led other major causes of injuries in woodworking [20]. The statistics on this finding is presented in Figure 3. In fact, it has been the most significant agent of woodworking injuries since 2013 [20]. Occupational injuries due to machines and equipment were very common in the manufacturing industry $(35.6 \%)$ where the woodworking sector is classified under [20]. In 2015, it accounted for more than half $(56.2 \%)$ of reported cases with workdays lost [20]. Based on these figures, inadequate management of equipment safety could, therefore, adversely impact the woodworking industry. Note that this industry is currently the country's leading economic component.

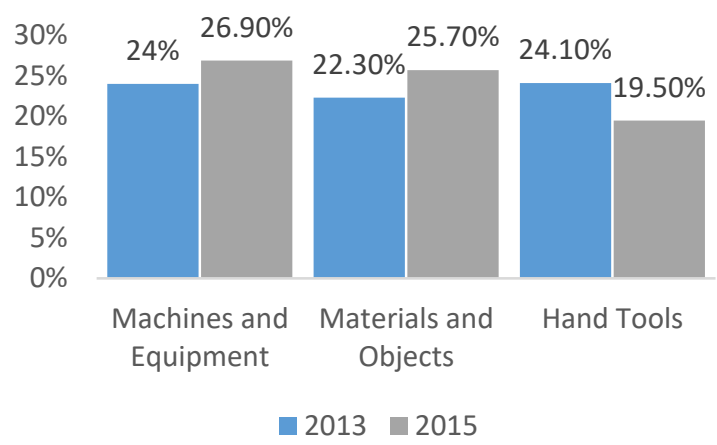

Figure 3. Top three agents of occupational injuries in the Philippines [20]

According to the Occupational Safety and Health Center (OSHC) [21], about 90\% of the Philippines' workforce do not enjoy favorable working conditions. They confirmed that safety conditions in low-income settings, including microfirms and the informal sectors, continue to be saddled with a host of risks and hazards in the country [21]. Substandard equipment and tools were among the hazards pointed out by the OSHC. In fact, the common hazards associated with woodworking are "being struck by hand tools and machines" and "caught by moving equipment" (e.g., [20, 21]). These injuries can result to workdays lost, which can be hefty to production lines employing hundreds of workers [21]. Thus, addressing the underlying problem does not only benefit the country's woodworking sector as its essential economic 
component, but it improves, to some extent, the welfare of the workers that benefit from the safety of operations.

\section{RESULTS AND DISCUSSIONS}

Using the FDM, the 44 WEHs were screened. As presented in Table 4 , the evaluations of all the five experts were consistent for all 44 WEHs. The value of $\alpha$ adopted in this paper is 7. This value has been consulted with the experts, which they unanimously agreed with. Those WEHs with the value of $G_{j}$ less than $\alpha$ are rejected and deleted from the initial list. After the procedure, $28 \mathrm{WEHs}$ were deleted and $16 \mathrm{WEHs}$ were accepted and considered relevant. Consequently, the accepted WEHs happened to be somewhat independent to technological solutions (e.g., sensors, automation). This may be due to the highly manual nature of woodworking equipment in developing countries.

Technologies like sensors, AI, and automation are not as widely adopted in developing countries like the Philippines. This indicates that WEHs that exhibit these characteristics are less relevant in these settings. However, highly manual woodworking equipment increase the number of OHSHs because they expose the limbs of operators to sharp equipment components more often than semi-automated woodworking equipment. Since the $16 \mathrm{WEHs}$ accepted herewith are deemed relevant for highly manual woodworking equipment, their assessment can facilitate the prioritization of WEHs. Measuring the importance of WEHs and prioritizing them on the basis of that measurement is essential for making optimal decisions in the innovation of the current design of woodworking equipment.

For prioritizing the $16 \mathrm{WEHs}$, the F-BWM is employed. Out of the five (5) experts considered in the first phase of this study, four (4) remained for the second phase due to personal reasons of one of the experts. Since three to 15 experts are required for taking on an expert decision-making problem [15], the four remaining experts are deemed sufficient for carrying on the F-BWM. The four experts all agreed that "kickback safeguards" (WEH26) as the best and "maintenance functions" (WEH28) as the worst WEH. Table 5 presents the linguistic responses of the experts. Using non-linear programming illustrated in model (14), the F-BWM models are developed for each expert. Using the models, the optimal fuzzy weights of WEHs are obtained per expert, as presented in Table 6.

In F-BWM, the consistency of expert judgments indicates the reliability of their response. According to Saaty [22], "a consistency ratio $(\mathrm{CR})$ of 0.1 or less is acceptable under the condition that all judgment matrices given by experts for the same problem of decision-making are of acceptable consistency". Guo and Zhao [18] emphasized that a consistency ratio close to zero indicates a high level of consistency. Based on the following points presented by two seminal papers in the field of MCDM, this paper employs a threshold value equivalent to 0.1 for the consistency of expert judgments in the F-BWM model. Based on the results, as presented in Table 7, the judgments of the four experts in this paper are consistent with all CR less than or equal to 0.1 . The weights were aggregated by averaging the deffuzified optimal weights per WEH. The aggregate weight indicates the relative importance of a WEH. This was used to rank the importance of WEHs, as presented in Table 8.
The results indicate that "kickback safeguards" (WEH26) is the most essential WEH with an aggregate optimal weight of 0.0874. Several studies have indicated particular importance to kickback of stock as among the most common hazards associated with woodworking equipment (e.g., [4, 23, 24]). Kickbacks can occur when a blade like that of a saw seizes the stock and hurls it back at the operator. This can happen when the stock twists and binds against the side of the blades or is caught in the teeth [2]. The leading cause of injuries suffered by workers in the Philippines which can be associated with kickback is "struck by objects (excluding falling objects)" which accounts for $39 \%$ of total injuries [20].

There are several reasons for a kickback, such as unsharpened blade, blades set at an incorrect height, and poor quality of lumber. It specified that "frozen lumber or lumber with many knots or foreign objects such as nails" can also result in kickbacks [2]. Previous studies even elaborated that some types of woods can have some sort of influence on kickbacks [25]. Hazards due to kickbacks are most likely to occur when there is lack of safeguards [2]. There are several design solutions proposed in previous literature to address this issue. Masse [23] proposed an innovative design of multipoint anti-kickback fingers for woodworking equipment. Some studies also propose a design for spreaders, gauge, and rip fences (e.g., [4, 24, 25]). The results of this paper suggest that, in low-income settings, especially those in developing countries, should focus on innovation that addresses kickback. With innovations in the current literature that suggest various designs of kickback safeguards, designers should have a plethora of ideas for addressing this issue.

The second most important WEH is "local exhaust ventilation" (WEH44) with an aggregate optimal weight of 0.0821 . Among the most common residues of woodworking is wood dust. Wood dust has been widely recognized in woodworking safety research as a potent carcinogen and allergen (e.g., [26, 27]). The guide [2] requires the development of engineering controls for physically changing woodworking equipment to prevent employee exposure to wood dust particles. Among these engineering controls are local exhaust ventilations. However, this installment might be challenging, especially for mobile woodworking equipment. Note that for local exhaust ventilation to be integrated at the source, it should be placed near the point of operation. This may be quickly deployed for stationary woodworking equipment, but can be of great challenge for mobile ones. Although several developments have been attempted to address this problem (e.g., [28, 29]), affordable designs that are tailored-fit to low-income settings has not yet been explored in previous literature.

Although some may argue that utilization of PPEs can quickly address the issue of wood dust; however, Abigail [30] elaborated that among the prevalent OHSHs in the informal manufacturing sector, which are especially rampant in lowincome settings, is the noncompliance of PPEs by organizations. Also, the guide [2] elaborates that all efforts to innovate woodworking equipment to reduce or eliminate WEHs should be exhausted before resorting to PPEs. Since the lack of adequate local exhaust ventilation has been pointed out as among the most essential WEH in this paper (WEH44), it warrants for more innovation efforts to address this WEH.

The third most important WEH is "shield guards" (WEH31) with an aggregate optimal weight of 0.0803 . There are several fatal cases in woodworking wherein equipment projectiles have been documented as reasons for critical injury or even 
death. The guide [2] made mention of a case wherein a piece of metal from a woodworking equipment broke down and projected towards operation and through the operator's chest, which caused his immediate death. According to the guide [2], improperly adjusted or poorly mounted cutter heads can become unbalanced, break down, and project sharp tools towards the operator. Consequently, a few woodworking equipment such as routers, shapers, and molders use rotating cutter heads with multiple knives. In the event that the knives are projected, only a shield guard can serve as the operators' defense. Although these incidents may occur not as frequent as other hazards, it is among the most fatal. Other incidents also include chips of wood and dust being projected to the operator's eyes [31].

For this reason, Pavlovic and Fragassa [32] attempted to develop flexible barriers used as safety protection. Several other studies either attempted to propose similar solutions for this WEH or recognized the importance for such (e.g., [13, 33, 34]). However, they also recognized that these innovations might obstruct operators during actual operation [8]. Although this is the case, given its fatal potential, it should not be discounted as among the most critical WEHs identified herewith. The results of this paper present sufficient warrant for further research to be carried out to discover adequate materials for shield guards, appropriate installation methods to minimize obstruction, among others.

By order of importance, the following are the rest of the WEHs with their respective aggregate optimal weights: "exposed blades" (WEH1) (0.0761), "rotary guards" (WEH20) (0.0749), "guards for in-running nip points" (WEH24) (0.0745), "cutter head stability" (WEH34) (0.0721), "crush protection mechanism" (WEH21) (0.0703), "guards at point of operation" (WEH7) (0.0702), "spindle brakes" (WEH23) (0.0651), "wheel brakes" (WEH17) (0.0540), "inspection panel" (WEH25) (0.0444), "stop controls" (WEH22) (0.0443), “interlock guards" (WEH10) (0.0423), "placement of controls" (WEH4) (0.0397), and "maintenance functions" (WEH28) (0.0225).

Table 4. Optimistic and conservative evaluation of experts and result of the FDM $(\alpha=7)$

\begin{tabular}{|c|c|c|c|c|c|c|c|c|c|c|c|c|}
\hline \multirow[b]{2}{*}{ No. } & \multicolumn{5}{|c|}{ Expert } & \multirow{2}{*}{$\frac{\check{\boldsymbol{o}}_{j}}{\left(L_{j}, M_{j}, U_{j}\right)}$} & \multirow{2}{*}{$\frac{\check{\boldsymbol{C}}_{j}}{\left(l_{j}, m_{j}, u_{j}\right)}$} & \multicolumn{3}{|c|}{ Gray interval } & \multirow[b]{2}{*}{ Consistency } & \multirow[b]{2}{*}{$\alpha-c u t$} \\
\hline & 1 & 2 & 3 & 4 & 5 & & & $\left(L_{j}, u_{j}\right)$ & $\left(m_{j}, M_{j}\right)$ & $\left(G_{j}\right)$ & & \\
\hline WEH26 & $(6,10)$ & $(6,9)$ & $(5,10)$ & $(7,10)$ & $(7,10)$ & $(9,9.79,10)$ & $(5,6.15,7)$ & $(9,7)$ & $(6.15,9.79)$ & 7.97 & Consistent & Accept \\
\hline WEH1 & $(6,10)$ & $(6,9)$ & $(6,9)$ & $(6,10)$ & $(7,10)$ & $(9,9.59,10)$ & $(6,6.19,7)$ & $(9,7)$ & $(6.19,9.59)$ & 7.89 & Consistent & Accept \\
\hline WEH7 & $(6,10)$ & $(6,9)$ & $(3,10)$ & $(7,10)$ & $(7,10)$ & $(9,9.79,10)$ & $(3,5.56,7)$ & $(9,7)$ & $(5.56,9.79)$ & 7.67 & Consistent & Accept \\
\hline WEH44 & $(5,10)$ & $(5,9)$ & $(5,9)$ & $(7,10)$ & $(7,10)$ & $(9,9.59,10)$ & $(5,5.72,7)$ & $(9,7)$ & $(5.72,9.59)$ & 7.65 & Consistent & Accept \\
\hline WEH25 & $(6,10)$ & $(5,9)$ & $(4,9)$ & $(7,10)$ & $(7,10)$ & $(9,9.59,10)$ & $(4,5.67,7)$ & $(9,7)$ & $(5.67,9.59)$ & 7.63 & Consistent & Accept \\
\hline WEH10 & $(6,10)$ & $(5,9)$ & $(4,9)$ & $(6,10)$ & & $(9,9.59,10)$ & $(4,5.5,7)$ & $(9,7)$ & $(5.5,9.59)$ & 7.54 & & Accept \\
\hline WEH17 & $(6,9)$ & $(5,8)$ & $(5,9)$ & $(7,10)$ & $(6,1$ & $(8,9.17,10)$ & & $(8,7)$ & & 7.46 & & Accept \\
\hline WEH22 & $(5,10)$ & $(4,9)$ & $(5,9)$ & $(7,10)$ & $(6,10)$ & $(9,9.59,10)$ & $(4,5.3,7)$ & $(9,7)$ & & 7.45 & Consistent & Accept \\
\hline WEH20 & $(6,10)$ & $(5,8)$ & $(4,9)$ & $(7,10)$ & $(6,10)$ & $(8,9.36,10)$ & $(4,5.5,7)$ & $(8,7)$ & $(5.5,9.36)$ & 7.43 & Consistent & Accept \\
\hline WEH34 & $(6,10)$ & $(4,8)$ & $(6,9)$ & $(6,10)$ & $(5,10)$ & $(8,9.36,10)$ & $(4,5.33,6)$ & $(8,6)$ & $(5.33,9.36)$ & 7.35 & Consistent & Accept \\
\hline WEH4 & $(6,10)$ & $(5,8)$ & $(4,9)$ & $(6,9)$ & $(7,10)$ & $(8,9.17,10)$ & $(4,5.5,7)$ & $(8,7)$ & & 7.34 & & Accept \\
\hline WEH23 & $(5,9)$ & $(4,8)$ & $(6,8)$ & $(7,10)$ & $(7,10)$ & $(8,8.96,10)$ & $(4,5.67,7)$ & $(8,7)$ & $(5.67,8.96)$ & 7.31 & Consistent & Accept \\
\hline WEH24 & $(5,10)$ & $(4,8)$ & $(4,9)$ & $(7,10)$ & $(7,10)$ & $(8,9.36,10)$ & $(4,5.23,7)$ & $(8,7)$ & $(5.23,9.36)$ & 7.30 & Consistent & Accept \\
\hline WEH21 & $(5,9)$ & $(3,8)$ & $(6,9)$ & $(7,10)$ & $(6,10)$ & $(8,9.17,10)$ & $(3,5.19,7)$ & $(8,7)$ & $(5.19,9.17)$ & 7.18 & & Accept \\
\hline WEH31 & $(5,10)$ & $(5,8)$ & $(4,9)$ & $(6,10)$ & $(5,10)$ & $(8,9.36,10)$ & $(4,4.96,6)$ & $(8,6)$ & $(4.96,9.36)$ & 7.16 & & Accept \\
\hline WEH28 & $(5,9)$ & $(4,8)$ & $(5,10)$ & $(5,10)$ & $(5,1$ & $(8,9.36,1$ & $(4,4.7$ & $(8,5)$ & $(4.78$, & 7.07 & & Accept \\
\hline WEH40 & & $(4,7)$ & $(5,10)$ & $(6,1$ & $(5$, & $(7,8.93$, & $(4,4.9)$ & (7, & & 6.94 & & eject \\
\hline WEH13 & $(5,8)$ & $(4,8)$ & $(4,8)$ & $(6,1$ & $(6,1)$ & $(8,8.75$, & $(4,4.9)$ & $(8$, & $(4.92$, & 6.83 & & ject \\
\hline WEH39 & $(5,9)$ & $(4,7)$ & $(4,9)$ & & & $(7,8.74,1$ & $(4,4.74,6)$ & (7, & $(4.74,8.74)$ & 6.74 & & Reject \\
\hline & $(6,10)$ & & $(4,9)$ & & & & & & & 6.69 & & Reject \\
\hline & & & $(4$, & & & & & & & & & eject \\
\hline & & $(4,7)$ & $(4$, & & & & & & & 6.61 & & eject \\
\hline & & $(4,7)$ & $(5,9)$ & $(7$, & & $(7,8$ & $(4,4$ & $(7,7)$ & (4. & 6.51 & & eject \\
\hline $\mathrm{H} 27$ & & $(4,7)$ & $(5,9$ & $(5$, & $(4,1$ & $(7,8$ & $(3,4$ & $(7,5)$ & (4. & 6.42 & & eject \\
\hline WE & $(4$ & $(3,7)$ & $(5,9$ & & & $(7,8$ & $(3,4$ & $(7,5$ & (4. & 6.24 & & eject \\
\hline WE & $(4,6)$ & $(3,7)$ & $(3,9)$ & $(6,1$ & $(6,1$ & $(6,8$ & $(3,4$ & $(6,6)$ & (4. & 6.21 & & eject \\
\hline H16 & $(5,7)$ & $(3,6)$ & $(4,9)$ & $(6,10)$ & & $(6,7.87,10)$ & $(3,4.48$ & $(6,6)$ & $8,7.87)$ & 6.18 & & Reject \\
\hline WEH43 & $(3,8)$ & $(3,6)$ & $(5,9)$ & $(6,10)$ & & $(6,8.09,10)$ & & $(6,6)$ & $(4.23,8.09)$ & 6.16 & & Reject \\
\hline WEH6 & $(5,9)$ & $(3,6)$ & $(4,10)$ & $(5,9)$ & & $(6,8.06,10)$ & & $(6,5)$ & $(4.13,8.06)$ & 6.09 & & Reject \\
\hline WEH42 & $(2,7)$ & $(3,7)$ & $(6,9)$ & $(6,10)$ & $(5,8)$ & $(7,8.12,10)$ & $(2,4.04,6)$ & $(7,6)$ & $(4.04,8.12)$ & 6.08 & & Reject \\
\hline WEH19 & $(4,7)$ & $(3,7)$ & $(5,9)$ & & $(4,8)$ & $(7,7.95,9)$ & $(3,4.13,5)$ & $(7,5)$ & $(4.13,7.95)$ & 6.04 & & Reject \\
\hline WEH30 & $(3,8)$ & $(3,6)$ & $(5,10)$ & & $(4,8)$ & $(6,7.9,10)$ & $(3,3.9,5)$ & $(6,5)$ & $(3.9,7.9)$ & 5.90 & Consistent & Reject \\
\hline WEH35 & $(5,7)$ & $(2,5)$ & $(6,9)$ & $(5,9)$ & $(4,8)$ & $(5,7.43,9)$ & $(2,4.13,6)$ & $(5,6)$ & $(4.13,7.43)$ & 5.78 & Consistent & Reject \\
\hline WEH38 & $(4,7)$ & $(3,6)$ & $(5,8)$ & $(6,7)$ & $(4,8)$ & $(6,7.16,8)$ & $(3,4.28,6)$ & $(6,6)$ & $(4.28,7.16)$ & 5.72 & Consistent & Reject \\
\hline WEH2 & $(2,7)$ & $(2,7)$ & $(5,9)$ & $(5,9)$ & $(5,8)$ & $(7,7.95,9)$ & $(2,3.47,5)$ & $(7,5)$ & $(3.47,7.95)$ & 5.71 & Consistent & Reject \\
\hline WEH32 & $(2,8)$ & $(4,6)$ & $(5,9)$ & $(5,8)$ & $(4,6)$ & $(6,7.3,9)$ & $(2,3.81,5)$ & $(6,5)$ & $(3.81,7.3)$ & 5.55 & Consistent & Reject \\
\hline & $(4,7)$ & $(2,5)$ & & & & $(5,7.26,9)$ & $(2,3.81,5)$ & $(5,5)$ & $(3.81,7.26)$ & 5.53 & & Reject \\
\hline & $(3,7)$ & $(3,7)$ & & & & $(5,7.07,9)$ & & $(5,5)$ & $(3.68,7.07)$ & 5.37 & & Reject \\
\hline & $(3,8)$ & $(1,6)$ & $(4,10)$ & & & $(6,7.63,10)$ & & $(6,5)$ & $(2.99,7.63)$ & 5.31 & & Reject \\
\hline & $(1,7)$ & $(3,5)$ & & & & $(5,7.07,9)$ & & & $(2.99,7.07)$ & 5.03 & Consistent & Reject \\
\hline & $(1,6)$ & $(1,5)$ & $(3,10)$ & & & & & & & 4.57 & & Reject \\
\hline WEH37 & $(2,6)$ & $(1,4)$ & $(5,9)$ & $(5,8)$ & $(3,5)$ & $(4,6.13,9)$ & $(1,2.72,5)$ & $(4,5)$ & $(2.72,6.13)$ & 4.43 & Consistent & Reject \\
\hline WEH36 & $(1,6)$ & $(1,4)$ & $(6,9)$ & $(5,8)$ & $(3,6)$ & $(4,6.36,9)$ & $(1,2.46,6)$ & $(4,6)$ & $(2.46,6.36)$ & 4.41 & Consistent & Reject \\
\hline WEH11 & $(1,5)$ & $(1,4)$ & $(5,9)$ & $(5,7)$ & $(3,7)$ & $(4,6.15,9)$ & $(1,2.37,5)$ & $(4,5)$ & $(2.37,6.15)$ & 4.26 & Consistent & Reject \\
\hline
\end{tabular}


Table 5. Linguistic evaluations of experts per WEH

\begin{tabular}{|c|c|c|c|c|}
\hline Best to others & Expert 1 & Expert 2 & Expert 3 & Expert 4 \\
\hline WEH26 to WEH1 & WI & WI & FI & EI \\
\hline WEH26 to WEH7 & EI & WI & FI & EI \\
\hline WEH26 to WEH44 & EI & EI & WI & EI \\
\hline WEH26 to WEH25 & FI & VI & VI & WI \\
\hline WEH26 to WEH10 & WI & VI & VI & WI \\
\hline WEH26 to WEH17 & WI & FI & FI & WI \\
\hline WEH 26 to WEH 22 & FI & VI & WI & FI \\
\hline WEH 26 to WEH20 & EI & WI & FI & EI \\
\hline WEH26 to WEH34 & WI & WI & WI & WI \\
\hline WEH 26 to WEH4 & FI & VI & FI & FI \\
\hline WEH26 to WEH23 & FI & WI & FI & WI \\
\hline WEH26 to WEH24 & EI & WI & FI & EI \\
\hline WEH26 to WEH21 & VI & FI & WI & EI \\
\hline WEH26 to WEH31 & EI & WI & FI & EI \\
\hline $\begin{array}{c}\text { WEH } 26 \text { to WEH } 26 \\
\text { Others to worst }\end{array}$ & EI & EI & EI & EI \\
\hline WEH1 to WEH28 & VI & VI & FI & VI \\
\hline WEH7 to WEH28 & VI & VI & FI & FI \\
\hline WEH44 to WEH28 & VI & AI & VI & FI \\
\hline WEH25 to WEH28 & FI & FI & FI & WI \\
\hline WEH10 to WEH28 & FI & WI & WI & WI \\
\hline WEH17 to WEH28 & FI & FI & FI & WI \\
\hline WEH 22 to WEH 28 & FI & WI & WI & WI \\
\hline WEH20 to WEH28 & AI & VI & FI & FI \\
\hline WEH34 to WEH28 & FI & VI & VI & FI \\
\hline WEH4 to WEH28 & WI & WI & WI & WI \\
\hline WEH 23 to WEH28 & FI & VI & FI & FI \\
\hline WEH24 to WEH28 & AI & VI & FI & FI \\
\hline WEH 21 to WEH 28 & VI & AI & VI & FI \\
\hline WEH31 to WEH28 & AI & AI & FI & FI \\
\hline $\begin{array}{c}\mathrm{WEH} 28 \text { to WEH } 28 \\
\text { Best to worst }\end{array}$ & EI & EI & EI & EI \\
\hline WEH26 to WEH28 & $\mathrm{AI}$ & $\mathrm{AI}$ & $\mathrm{AI}$ & $\mathrm{AI}$ \\
\hline
\end{tabular}

Table 6. Optimal fuzzy weights per WEH of each expert

\begin{tabular}{ccccc}
\hline WEH No. & Expert 1 & Expert 2 & Expert 3 & Expert 4 \\
\hline WEH26 & $(0.0896,0.0896,0.099)$ & $(0.0858,0.0961,0.1063)$ & $(0.0769,0.0769,0.0951)$ & $(0.0793,0.0793,0.098)$ \\
WEH1 & $(0.071,0.071,0.0803)$ & $(0.049,0.0755,0.0755)$ & $(0.0557,0.0637,0.0789)$ & $(0.0937,0.0937,0.1061)$ \\
WEH7 & $(0.071,0.071,0.0803)$ & $(0.049,0.0755,0.0858)$ & $(0.0557,0.0637,0.0789)$ & $(0.0671,0.069,0.0814)$ \\
WEH44 & $(0.071,0.071,0.0803)$ & $(0.0636,0.0961,0.1063)$ & $(0.0909,0.0909,0.1029)$ & $(0.0671,0.069,0.0814)$ \\
WEH25 & $(0.0501,0.0524,0.0617)$ & $(0.0376,0.0413,0.0469)$ & $(0.0348,0.0348,0.045)$ & $(0.0428,0.0443,0.0566)$ \\
WEH10 & $(0.0501,0.0524,0.0617)$ & $(0.0255,0.0344,0.0344)$ & $(0.0348,0.0348,0.045)$ & $(0.0428,0.0443,0.0566)$ \\
WEH17 & $(0.0501,0.0524,0.0617)$ & $(0.0335,0.0549,0.0549)$ & $(0.0557,0.0637,0.0789)$ & $(0.0428,0.0443,0.0566)$ \\
WEH22 & $(0.0501,0.0524,0.0617)$ & $(0.0255,0.0344,0.0344)$ & $(0.0415,0.043,0.0549)$ & $(0.0428,0.0443,0.0566)$ \\
WEH20 & $(0.0896,0.0896,0.099)$ & $(0.049,0.0755,0.0858)$ & $(0.0557,0.0637,0.0789)$ & $(0.0671,0.069,0.0814)$ \\
WEH34 & $(0.0501,0.0524,0.0617)$ & $(0.049,0.0755,0.0755)$ & $(0.0909,0.0909,0.1029)$ & $(0.0671,0.069,0.0814)$ \\
WEH4 & $(0.0321,0.0337,0.043)$ & $(0.0255,0.0344,0.0344)$ & $(0.0415,0.043,0.0549)$ & $(0.0428,0.0443,0.0566)$ \\
WEH23 & $(0.0501,0.0524,0.0617)$ & $(0.049,0.0755,0.0755)$ & $(0.0557,0.0637,0.0789)$ & $(0.0671,0.069,0.0814)$ \\
WEH24 & $(0.0896,0.0896,0.099)$ & $(0.049,0.0755,0.0755)$ & $(0.0557,0.0637,0.0789)$ & $(0.0671,0.069,0.0814)$ \\
WEH21 & $(0.0368,0.0409,0.053)$ & $(0.0582,0.0723,0.1035)$ & $(0.0909,0.0909,0.1029)$ & $(0.0671,0.069,0.0814)$ \\
WEH31 & $(0.0896,0.0896,0.099)$ & $(0.0858,0.0961,0.0961)$ & $(0.0557,0.0637,0.0789)$ & $(0.0671,0.069,0.0814)$ \\
WEH28 & $(0.0186,0.0186,0.0217)$ & $(0.0206,0.0206,0.0206)$ & $(0.024,0.024,0.0284)$ & $(0.0247,0.0247,0.0293)$ \\
\hline
\end{tabular}

Table 7. Deffuzified optimal weights, $\xi$, consistency index, and consistency ratio per expert

\begin{tabular}{ccc}
\hline Woodworking equipment hazards & Consistency index & Consistency ratio \\
\hline Expert 1 & 8.04 & 0.100 \\
Expert 2 & 8.04 & 0.084 \\
Expert 3 & 8.04 & 0.098 \\
Expert 4 & 8.04 & 0.098 \\
\hline
\end{tabular}


Table 8. Aggregate weight per WEH and their standard deviation

\begin{tabular}{cccc}
\hline Woodworking equipment hazards & Average weight & s.d. & Rank \\
\hline Kickback safeguards (WEH26) & 0.0874 & 0.0065 & 1 \\
Exposed blades (WEH1) & 0.0761 & 0.0117 & 4 \\
Guards at point of operation (WEH7) & 0.0702 & 0.0032 & 9 \\
Local exhaust ventilation (WEH44) & 0.0821 & 0.0105 & 2 \\
Inspection panel (WEH25) & 0.0444 & 0.0062 & 12 \\
Interlock guards (WEH10) & 0.0423 & 0.0081 & 14 \\
Wheel brakes (WEH17) & 0.0540 & 0.0069 & 11 \\
Stop controls (WEH22) & 0.0443 & 0.0074 & 13 \\
Rotary guards (WEH20) & 0.0749 & 0.0099 & 5 \\
Cutter head stability (WEH34) & 0.0721 & 0.0140 & 7 \\
Placement of controls (WEH4) & 0.0397 & 0.0058 & 15 \\
Spindle brakes (WEH23) & 0.0651 & 0.0071 & 10 \\
Guards for in-running nip points (WEH24) & 0.0745 & 0.0100 & 6 \\
Crush protection mechanism (WEH21) & 0.0703 & 0.0182 & 8 \\
Shield guards (WEH31) & 0.0803 & 0.0127 & 3 \\
Maintenance functions (WEH28) & 0.0225 & 0.0027 & 16 \\
\hline
\end{tabular}

\section{CONCLUSION AND FUTURE WORKS}

Based on expert judgment in the Philippine setting, this paper was able to measure the relative importance of WEHs using an integrated fuzzy MCDM model based on FDM and F-BWM. The relative importance of the WEHs may be utilized for various applications involving decision making in safety management of woodworking equipment. The proposed algorithmic framework in this study can help managers, occupational safety and health professionals (OSHPs), and woodworking firms in developing countries like the Philippines to build the capability they need to address WEHs and, to some extent, improve safety practices in the woodworking industry. In particular, the framework developed herewith can help safety managers in prioritizing designs to address specific WEHs, OSHPs in assessing the safety of woodworking equipment, and woodworking firms in developing countries in improving their current practices, as well as implementation paths, more effectively.

This paper does have several limitations, which warrants for additional research. The limitations provide ample room for improvement. Also, it can provide useful basis for further research into this subject. One of the principal limitations of this paper is its exploratory nature. The result presented in this paper only considers a particular woodworking sector in one region (Philippines), which makes it difficult to generalize the findings. Broader empirical research is, therefore, required. The results also cover a single period of study. However, in the view of the researchers, this paper helps lay the foundations for a research topic that will only gain in importance in years to come.

\section{REFERENCES}

[1] Himang, C.M., Beltran, H.U., Ocampo, L., Garcia II, J.M.S., Ancheta Jr, R.A., Himang, M.M., Selerio Jr., E.F., Luzano, E.J.I. (2020). Acceptability evaluation of a developed thermal infrared device for fire risk management: Using the unified theory of acceptance and use of technology (UTAUT) model. International Journal of Sociotechnology and Knowledge Development (IJSKD), 12(3): 1-25. http://dx.doi.org/10.4018/IJSKD.2020070101

[2] Occupational Safety and Health Administration (OSHA).
(1999). Guide for Protecting Workers from Woodworking Hazards. Small Business Safety Management Series. U.S. Department of Labor. https://www.osha.gov/Publications/woodworking_hazar ds/osha3157.html.

[3] Arimbi, H.B., Puspasari, M.A., Syaifullah, D.H. (2019). Hazard identification, risk assessment and risk control in a woodworking company. IOP Conference Series: Materials Science and Engineering, 505(1): 012038. http://dx.doi.org/10.1088/1757-899X/505/1/012038

[4] Dąbrowski, M., Górski, J. (2019). Mobile shields for standard woodworking machinery as an element of a protection and accident prevention system-the idea and testing. BioResources, 14(2): 3459-3470.

[5] Gunduz, M., Ahsan, B. (2018). Construction safety factors assessment through frequency adjusted importance index. International Journal of Industrial Ergonomics, 64: 155-162. http://dx.doi.org/10.1016/j.ergon.2018.01.007

[6] Sheldon, D., Singh, K. (2018). U.S. Patent No. 10,016,868. Washington, DC: U.S. Patent and Trademark Office.

[7] Chukarin, A.N., Buligin, Y.I., Alexeenko, L.N., Romanov, V.A. (2017). Integrated development of noisedust woodworking machines at the design stage. IOP Conference Series: Earth and Environmental Science, 50(1): $\quad 012014 . \quad$ http://dx.doi.org/10.1088/17551315/50/1/012014

[8] Pavlovic, A., Fragassa, C. (2017). Numerical modelling of ballistic impacts on flexible protection curtains used as safety protection in woodworking. Proceedings of the Institution of Mechanical Engineers, Part C: Journal of Mechanical Engineering Science, 231(1): 44-58. http://dx.doi.org/10.1177/0954406216638888

[9] Weaver III, A., Callahan, G., Hearn, A., McCall, J. (2019). Band saw safety technologies: flesh-sensing mechanisms and other devices. Professional Safety, 64(12): 35-41.

[10] Gass, S.F. (2018). U.S. Patent No. 9,927,796. Washington, DC: U.S. Patent and Trademark Office.

[11] Fragassa, C., Lucisano, G., Marinković, D., Campana, G. (2019). A practical guideline in the design and use of woodworking tools. FME Transactions, 47(3): 487-495. http://dx.doi.org/10.5937/fmet1903487F

[12] Reinert, D., Schwaneberg, O., Jung, N., Ullmann, S., 
Olbert, W., Kamin, D., Kohler, R. (2009). Finger and hand protection on circular table and panel saws. Safety Science, 47(8):

$1175-1184$ http://dx.doi.org/10.1016/j.ssci.2009.01.003

[13] Loisel, F., Bonin, S., Jeunet, L., Pauchot, J., Tropet, Y., Obert, L. (2014). Woodworking injuries: A comparative study of work-related and hobby-related accidents. Chirurgie de la Main, 33(5): 325-329. http://dx.doi.org/10.1016/j.main.2014.06.003

[14] Fadier, E., Ciccotelli, J. (1999). How to integrate safety in design: Methods and models. Human Factors and Ergonomics in Manufacturing, 9(4): 367-379. http://dx.doi.org/10.1002/(SICI)15206564(199923)9:4<367::AID-HFM4>3.0.CO;2-A

[15] Manoliadis, O., Tsolas, I., Nakou, A. (2006). Sustainable construction and drivers of change in Greece: A Delphi study. Construction Management and Economics, 24(2): 113-120. http://dx.doi.org/10.1080/01446190500204804

[16] Zadeh, L.A. (1965). Fuzzy sets. Information and Control, 8(3): 338-353. http://dx.doi.org/10.1016/S00199958(65)90241-X

[17] Sultana, I., Ahmed, I., Azeem, A. (2015). An integrated approach for multiple criteria supplier selection combining fuzzy Delphi, fuzzy AHP and fuzzy TOPSIS. Journal of Intelligent and Fuzzy Systems, 29(4): 12731287. http://dx.doi.org/10.3233/IFS-141216

[18] Guo, S., Zhao, H. (2017). Fuzzy Best-Worst multicriteria decision-making method and its applications. Knowledge-Based Systems, 121: 23-31. http://dx.doi.org/10.1016/j.knosys.2017.01.010

[19] Philippine Statistics Authority (PSA). (2017). Monthly Integrated Survey of Selected Industries: January 2017. https://psa.gov.ph/content/monthly-integrated-surveyselected-industries-january-2017.

[20] Philippine Statistics Authority (PSA). (2018). Safety and Health in the Workplace: Types of Injuries, Parts of Body Injured, Causes and Agents of Injuries. LABSTAT Updates, 22(3). http://www.psa.gov.ph/sites/default/files/attachments/ir d/specialrelease/LABSTAT\%20Updates $\% 20 \mathrm{Vol} . \% 202$ 2\%20No.\%203.pdf

[21] Occupational Safety and Health Center (OSHC). (2006). National Profile on Occupational Safety and Health. http://oshc.dole.gov.ph/images/Files/Info\%20Materials/ National-OSH-Profile.pdf.

[22] Saaty, T.L. (1980). The Analytic Hierarchy Process. McGraw-Hill, New York.

[23] Masse, S. (2000). Design of multipoint anti-kickback fingers for woodworking machines. Transactions of the Canadian Society for Mechanical Engineering, 24(1A):
45-59. http://dx.doi.org/10.1139/tcsme-2000-0003

[24] Sabongi, R.G., Erazo, J.P., Moraes, V.Y.D., Fernandes, C.H., Santos, J.B.G.D., Faloppa, F., Belloti, J.C. (2019). Circular saw misuse is related to upper limb injuries: A cross-sectional study. Clinics, 74. http://dx.doi.org/10.6061/clinics/2019/e1076

[25] Dąbrowski, A. (2015). Kickback risk of portable chainsaws while cutting wood of different properties: Laboratory tests and deductions. International Journal of Occupational Safety and Ergonomics, 21(4): 512-523. http://dx.doi.org/10.1080/10803548.2015.1095547

[26] IARC. (1995). IARC Monographs on the Evaluation of Carcinogenic Risks to Humans. Wood Dust and Formaldehyde. Lyon: IARC, 62. https://monographs.iarc.fr/wpcontent/uploads/2018/08/14-002.pdf.

[27] Löfstedt, H., Hagström, K., Bryngelsson, I.L., Holmström, M., Rask-Andersen, A. (2017). Respiratory symptoms and lung function in relation to wood dust and monoterpene exposure in the wood pellet industry. Upsala Journal of Medical Sciences, 122(2): 78-84. http://dx.doi.org/10.1080/03009734.2017.1285836

[28] Kawamata, T., Yonekawa, H., Nishikawa, T., Horie, N., Inagawa, H., Katou, K. (2012). U.S. Patent Application No. 13/353,835.

[29] Brewster, M.R., Wong, T.K., Lam, C.H., Wattenbach, B.P., Verbrugge, B.L., Vögele, R., Limberg, K., Chen, M.C. (2017). U.S. Patent No. 9,776,296. Washington, DC: U.S. Patent and Trademark Office.

[30] Abigail, N.O. (2016). Occupational health and safety issues in the informal manufacturing sector of cape coast metropolis. Doctoral dissertation, University of Cape Coast. https://erl.ucc.edu.gh/jspui/handle/123456789/3070.

[31] Chung, B.H.J. (2018). U.S. Patent No. 10,076,796. Washington, DC: U.S. Patent and Trademark Office.

[32] Pavlovic, A., Fragassa, C. (2016). Analysis of flexible barriers used as safety protection in woodworking. International Journal for Quality Research, 10(1): 71-88.

[33] Heisel, U., Forcillo, V. (2014). Bulletproof and noisereducing guards in lightweight design for woodworking machines. Advanced Materials Research, 907: 41-54. http://dx.doi.org/10.4028/www.scientific.net/AMR.907. 41

[34] Berhe, A., Yemane, D., Gebresilassie, A., Terefe, W., Ingale, L. (2015). Magnitude of occupational injuries and associated factors among small-scale industry workers in Mekelle City, Northern Ethiopia. Occupational Medicine and Health Affairs, 3(3): 1000197. http://dx.doi.org/10.4172/2329-6879.1000197 